\title{
Effect electric pulse application on the fruit body production of Tricholoma matsutake-In situ condition
}

\author{
Ferzana Islam ${ }^{1}$, Afsana Islam ${ }^{2}$, Shoji Ohga ${ }^{1}$ * \\ ${ }^{1}$ Department of Agro-environmental Sciences, Faculty of Agriculture, Kyushu University, Fukuoka 811-2415, Japan \\ ${ }^{2}$ Institute of Molecular Bioscience, Massey University, University of New Zealand
}

Received on 13 November 2012, revised on 13 January 2013, accepted on 1 February 2013

\begin{abstract}
Effect of electric pulse stimulation was tested on the fruit body formation of valuable mushroom Tricholoma matsutake in the field of natural habitat of this mushroom. After applying the electric stimulator to the specific area of pine forest we found that the treatment especially stimulated the fructification of $T$. matsutake. And the most valuable findings of our study was that only our treatment plots showed fruit body formation whereas the control plots and the whole natural habitats of our study area showed zero production of this mushroom during the same time. From the point of view of mushroom production, our experiment shows that fruit body production can be upgraded by using pulsed power as an electrical stimulation in the field of the natural habitat of this mushroom. These findings from our experiment confirm the effectiveness of the significance of pulsed power technology for the improvement of T. matsutake fruit body production in the natural habit of this mushroom.
\end{abstract}

Key words : Ectomycorrhiza, Tricholoma matsutake, Fruit body, Electric pulse stimulation, Natural habitat

\section{Introduction}

Japan produces the best quality Tricholoma matsutake in the whole world. Commonly in Japan T. matsutake is known as 'Matsutake', this is a mushroom of coniferous woodlands and primarily occurs within the Japanese red pine (Pinus densiflora Sieb. et Zucc) forests (Ito, 2000). Ectomycorrhizal fungi play an important role by forming symbiotic associations with many woody plant species. Economically T. matsutake is an important ectomycorrhizal fungus in Japan where it holds its exceptional commercial value as a highly sought edible mushroom (Hall et al., 2003) comparing to others. This mushroom is more than just a seasonal delicacy as being a part of Japanese culture. However, over the last few decades the local production of this valuable mushroom has severely decreased, and as a result Japan is also importing matsutake from other

*Corresponding author: Tel: +82-92-948-3116

E-mail address: ohga@forest.kyushu-u.ac.jp countries (Yun et al., 1997). In the year of 1941, the annual harvest of $T$. matsutake showed a sharp rise which peaked around 12,000 tones, whereas in 2005 the production fall down to only 34 tons in Japan (Kinoko, 2008). The decline in the production of this valuable mushroom is due to several reasons. From the year 1998 to 2010 in the wholesale mushroom market of Japan, $T$. matsutake price showed a sharp rise from 180 to 439 US Dollar. Whereas, the market prices of other mushroom were below 12 US Dollar (Ministry of Agriculture, Forestry and Fisheries of Japan, 2011). Hence, enhancement of local production of T. matsutake should always be welcome.

While giving an importance on 'matsutake' cultivation, the natural habitat of T. matsutake cannot be taken out of account. The reason is, research attempts to establish synthetic 'musutake' cultivation on a large scale production basis, still remained under scientific investigation for nearly a century. Lot of scientific attention is required for emphasizing on the natural 
habitat to boost up the production under in situ conditions. Utilizing of electric energy has been extended for different agricultural crops, particularly in horticultural areas in Japan. Application of electrical stimulation has improved the cultivation technologies for green house crops such as strawberry, tomato, lettuce and various flowers. In this aspect, promising results have been found from research with electric power stimulator technology. Experiments under controlled conditions were conducted to improve mushroom cultivation at research centers since 1950s, which signifies the success of this technology. Recently, electrical sources like high voltage waves or pulses are being used for the improvement of edible and medicinal mushroom culture (Ohga et al., 2001 ; Ohga and Iida, 2001 ; Tsukamoto et al., 2005; Ohga, 2012; Islam and Ohga, 2012). Hence, we hypothesize that by applying pulse stimulation around the the naturally occurring T. matsutake areas of pine forests is a way to overcome the pitfall of the 'matsutake' production in Japan. In our research work, we considered the specific area for the production of this specific mushroom in the pine forest which is strictly restricted by the 'matsutake' growers of Japan.

\section{Materials and Methods}

\section{Study area}

Our present study was conducted at Uda city, Nara Prefecture pine forests having central co-ordinates $34^{\circ}$ $35^{\prime} \mathrm{N}$ and $136^{\circ} 2^{\prime} \mathrm{E}$, on the western part of Japan. The forest area which belongs to private property, the natural habitat of $T$. matsutake is highly restricted, for the production of this mushroom. A total of $36 \mathrm{~m}^{2}$ land was rented for the purpose of our study and exclusive permission was obtained to enter the cultivation premise. The pine forest is located at an altitude between 350 and $470 \mathrm{~m}$ above sea level. The annual air temperature for the year 2012 has been recorded $12.0^{\circ} \mathrm{C}$ and precipitation 2,009 $\mathrm{mm}$. The soil $\mathrm{pH}$ ranges from 5.0 to 6.0 outside the (shiro) mycelium while inside (shiro) the range was from 4.5 to 5.5 during fruit body formation. Naturally regenerated $P$. densiflora it the dominated plant species, which are 40 to 60 year old. The soil developed from volcanic lava consisting of mainly granite and a variety of parent materials, as well with scattered patches of bare soil. Nature of the soil is sandy loam texture and land topography contributes to the well-drained features, generally poor fertile soils and acidic in reaction. Mosses and litter layer covering in the forest have a thickness between 0.5 and $10 \mathrm{~cm}$. The experiment was carried out during late September and until the end of October, 2012, to know the effect of pulse stimulation on the production of T. matsutake. The layout of our experimental setup is represented in Fig. 1. Electric pulse stimulation was applied selected areas on three plots having a measurement of the plots, $3 \times 2 \mathrm{~m}$ which were surrounded by three to five $P$. densiflora trees. Control plots were also included in our experiment and they were located in the opposite sides (Fig. 1) of each treatment plot. The treatment plots were chosen randomly, and situated far distance (approximately more than $100 \mathrm{~m}$ ) from each other.

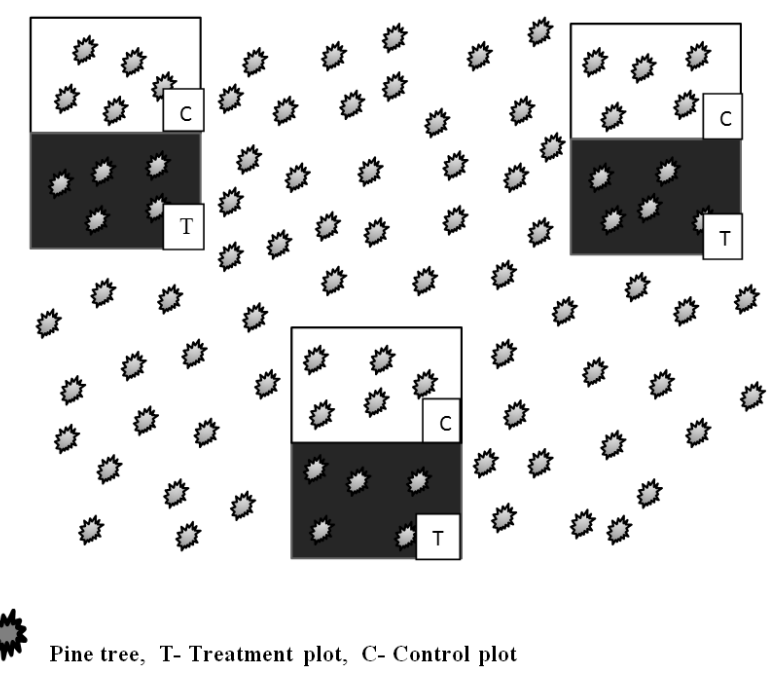

Fig. 1. Layout of the experimental setup. Plots defined with $T$ was treated with the application of electric pulse stimulation, and the plots defining with $\mathrm{C}$ was the control plots with no electric stimulation. 


\section{Application of electric pulse stimulation treatment}

A Pulse power generator (Fig. 2) was used in our study built by "Yushin Electrical Technology" Toyota Company (Islam and Ohga, 2012). Electric pulse stimulation was applied through the electrode wheels which were driven along the ground. It was applied on the ground in form of lightning and was a constant application. Pulse application was applied for one time during the experiment. High pulse voltage of 50 $\mathrm{kV}$ was applied to three different treatment plots of T. matsutake.

\section{Mycorrhizal fruit body observation}

Formation of $T$. matsutake fruit body usually takes place from the period of early September to the end of October. The fruit body appearances in our study were recorded during the whole fruiting season, two weeks after electric stimulation treatment. To measure the number, weight, length and production of freshly harvested mushrooms sampling scheme was followed randomly. Fruit bodies were collected and recorded in 6 plots during flushing. Using the whole plot technique number, weight and individual length of fruit bodies were recorded in situ. After recording that, T. matsutake production was calculated per meter square basis.

Data were analyzed statistically and their mean differences were evaluated with students t-test using the SPSS statistical software package (v. 15.0; SPSS Inc., Chicago, IL, USA).

\section{Results and Discussion}

Identified fruit bodies of T. matsutake were collected from the plots (Fig. 3). Near about 11 fruit bodies were collected during the fruiting period. Approximately mean number of fruit bodies was 3 to 4 from treatment plots, and 0 from the control plots were recorded, they were harvested during flushing. Fruit body formation was affected significantly (Fig. 4a) by the application of electrical stimulation. These revealed highly significant differences. The number of fruit body formation ratio (yield on treatment plot/ yield on control plot ) indicated $111 \%$ by the electric pulse stimulation treatment.

Mean weight of (per one) fruit body was approximately $109 \mathrm{~g}$ from the treatment plots which showed highly significant effect (Fig. 4b). The mean length of (per one) sporocarp was near about $10.77 \mathrm{~cm}$ in electrical stimulated plots and was also showed highly

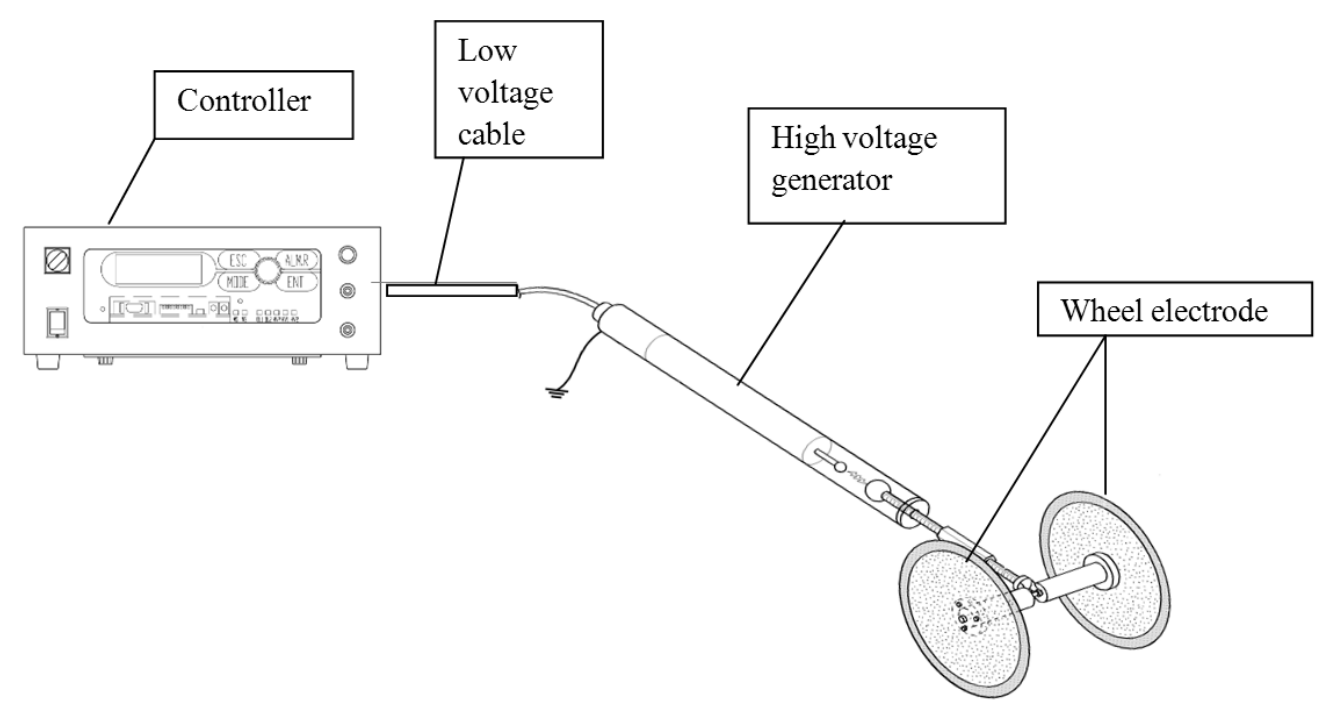

Fig. 2. Schematic diagram of the apparatus used for applying electric pulse stimulation. 


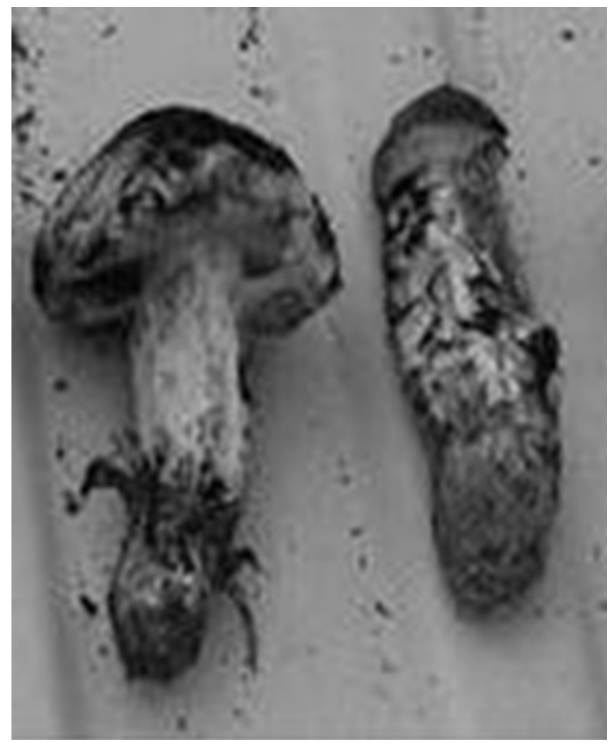

Fig. 3. Some collected Tricholoma matsutake from the treatment plots.
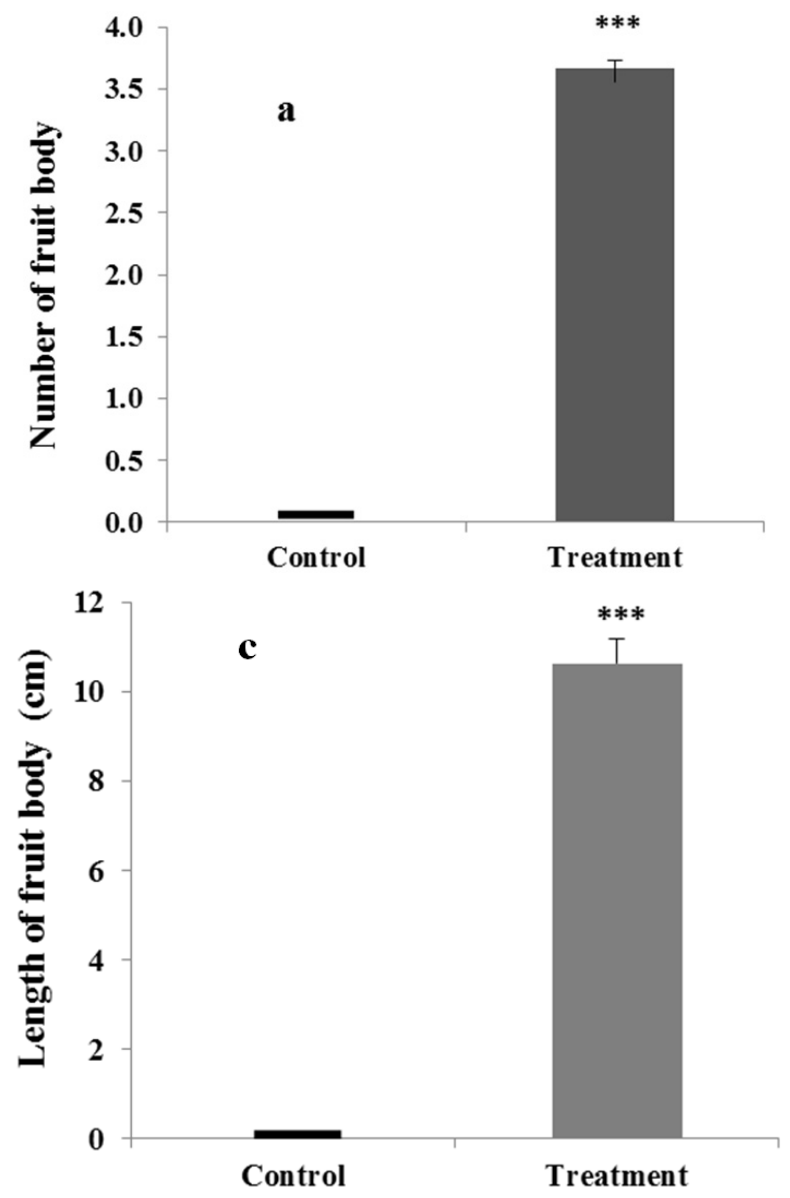

significant (Fig. 4c) comparing treated and control plots. Our experiment showed excellent qualities of the fruit bodies which were $10900 \%$ and $1077 \%$ for weight and length, in the same time there was no fruit body formation on the control plots. Production from the treatment plots were approximately $18.25 \mathrm{~g} / \mathrm{m}^{2}$. Production was found $1825 \%$ on the treatment plots. Productions between treatment and control plots showed highly significant differences. Judging for the significant differences were found (Fig. 4d).

Ectomycorrhizal fungi are very important and considered as widespread components of the ecosystem. Our present study focused on the fruit body production of T. matsutake by applying electrical stimulation in the Japanese red pine forest. Researchers found an
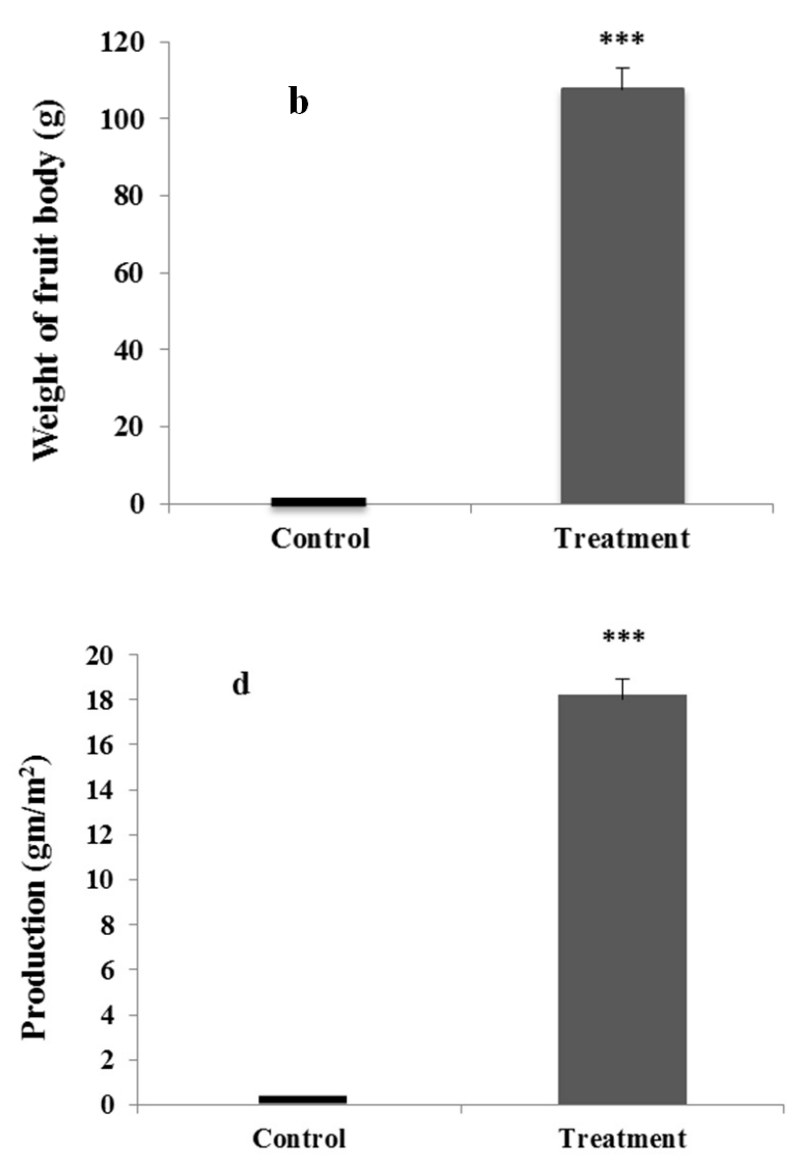

Fig. 4. a. Effect of electrical stimulation on the number of Fruit body formation. b. Effect of electrical stimulation on the weight of Fruit body. c. Effect of electrical stimulation on the length of Fruit body. d. Effect of electrical stimulation on the production of Tricholoma matsutake. The level of significance was analyzed by ANOVA with pair t-test. Data are expressed as mean \pm S.E.M. ( $n=3$ per group). Asterisk indicates significant differences $\left({ }^{*} \mathrm{P}<0.001\right)$ from the control. 
increase in production mushroom from their research through pulsed high voltage and the yield was twice as much as those which were not subjected to the electrical stimulus (Ferzana and Ohga, 2012; Ohga, 2012). Our research findings from study confirmed that the sporocarp formation of $T$. matsutake was promoted by the application of electrical stimulation. This phenomenon might be a reason as a response of external application of electric pulse stimulation on the mycorrhizal physiology.

We found that fruit body formation only taken place in the treatment plots. Most of the plant species can generate a significant amount of acetaldehyde and ethanol at an ambient level when they are exposed to environmental stress such as water deficit, low temperature, thunder storm and ozone exposure (Gooday, 1975; Kerns et al., 1993) (McGilivray and Gow, 1986; Robinson, 1985), which can play an important role on the mycorrhizal symbiosis. Among mushroom farmers (based on their experiences) it is well known that around the hit point of lightening, the mushroom grow up extraordinarily, after several days from the lightning. The mushroom outbreak mechanism is not clear, but there are two possibilities which are suggested by some of the researchers. One is the cracks that are formed in mycelium hyphae from the result of lightning, because hyphae produce fruit bodies from cracks and another one is the enzyme activity (Ohga et al., 2001 ; Ohga and Iida, 2001). This is might be one of the reasons that the treatment plots only gave fruit body formation than the control ones. The T. matsutake mycelia may be responded to the applied electric pulse stimulator to stimulate the fruiting process.

We have analyzed the influence of electric pulse stimulation on the fruit body production per meter square basis in Japanese red pine forest. Ectomycorrhizal fungi T. matsutake showed rich production of fruit body. The fruit body production was obviously affected by the electric pulse stimulation (Islam and Ohga, 2012). The improvement of fruiting body formation might be the effect derived from some specific activation at the enzyme level after the application of pulse electricity. Some scientists (Robinson, 1985; McGillivray and Gow, 1986) suggested that fungi of different kinds shows different behaviors when they are stimulated through applied electric field: hyphal extension direction, germ tube formation and branching, branching frequency and germination all could be affected. The cracking phenomenon of mycelia was observed by the pulsed power treatment on some mushroom resulted mycelia density incensement which concluded the main effect of fructification promotion of mushroom (Ohga, 2012). These reasons might be a reason to play an important role on the production as all as fruit body formation of $T$. matsutake.

Exogenous energy field might play an important role when the mycelia are exposed to it. Still now the mechanism of electrical stimulation effects was not studied. Hence, it is difficult for us to make generalization. From the point of ecological view, ectomycorrhizae are one of the most important groups in forest systems which plays essential interfaces between soil and trees. The fruit body production mechanisms of $T$. matsutake in Japanese red pine forest were significantly influenced by electric pulse stimulation. Probably it is the result caused which is caused by a specific stimulation on the formation of primordium in $T$. matsutake. It is really difficult to determine the mechanisms which were operating in the ectomycorrhizal physiology from our research, because only fruit body formation was studied.

\section{Conclusion}

As the fruit body formation of T. matsutake under artificial condition did not reach any significant result till now, so our present study has been made in developing methods to maximize the production in forests (natural habitats). In this research article, we gave evidence that the technology of pulse power 
stimulation can successfully improve the production of T. matsutake. Our study proved that electric stimulation had a very important effect on flushing of T. matsutake, because besides our treatment plots there was no natural T. matsutake fruit body production (including our control plots) around the whole specific pine forest area of Nara prefecture, during the same year (2012) when our study was conducted. Techniques of applying electric pulse stimulation on natural T. matsutake occurring sites can have a bright future for the research work on this valuable mushroom. Making continuation of the results we hope to do further more studies on T. matsutake as it was limited to one habitat type, in different red pine forest habitats in Japan, including other mushrooms, host interaction, their physiological and biological changes,

\section{Acknowledgements}

These studies were supported by Kyoeisya Chemical Co. Ltd., Nara 630-8453, Japan and Yushin Electric Technology Co. Ltd., Toyota 471-0855, Japan.

\section{References}

Gooday G W. 1975. Chemotaxis and chemotropism in fungi and algae. in Premitive Sensory and Communication Systems. M. J. Carlile. Ed. Academic Press. London. UK. pp 155-204.
Hall I R, Yun W, Amicucci A. 2003. Cultivation of edible ectomycorrhizal mushrooms. Trends in Biotechnology 21(10): 433-438.

Islam F, Ohga S. 2012. The response of fruit body formation on Tricholoma matsutake In Situ condition by applying Electric pulse stimulator. International Scholarly Research Network. doi:10.5402/ 2012/462724.

Ito T. in: Ogawa M, Kinugawa K. 2000. Eds. Mushroom. Handbook. Asakura. Japan, pp 9-21.

Kerns G, Bauer E, Berg H. 1993. Electrostimulation of cellulase fermentation by pulsatile electromagneticcally induced current. Bioelectrochemistry and Bioenergetics 32(1):89-94.

Kinoko N. 2008. Plants world. Tokyo. Japan.

McGillivray A M, Gow N A R. 1986. Applied electrical fields polarize the growth of mycelial fungi. Journal of General Microbiology 132(9):2515-2525.

Ministry of Agriculture. 2011. Forestry and Fisheries of Japan.

Ohga S, Iida S, Koo C D, Cho N S. 2001. Effect of electric impulse on fruit body production of Lentinula edodes in the sawdust- based substrate. Journal of the Japanese Society of Mushroom Science and Biotechnology 9(1):7-12.

Ohga S, Iida S. 2001. Effect of electric impulse on sporocarp formation of ectomycorrhizal fungus Laccaria laccata in Japanese red pine plantation. Journal of Forest Research 6(1):37-41.

Ohga S. 2012. Application of electric pulse power on fruit body production of edible and medicinal mushrooms. CNU Journal of Agricultural Science 39(4):591-594.

Robinson K R. 1985. The responses of cells to electrical fields: a review. Journal of Cell Biology 101(6):2023-2027.

Tsukamoto S, Kudoh H, Ohga S, Yamamoto K, Akiyama H. June, 2005. Development of an automatic electrical stimulator for mushroom sawdust bottle. in Proceeding of the $15^{\text {th }}$ Pulsed Power Conference. Monterey. Calif. USA. pp 1437-1440.

Yun W, Hall I R, Evans L A. 1997. Ectomycorrhizal fungi with edible fruiting bodies. 1. Tricholoma matsutake and related fungi. Economic Botany 51(3):311-327. 